Journal of Engineering and Applied Sciences 5 (2): 56-63, 2010

ISSN: 1816-949X

(C) Medwell Journals, 2010

\title{
Implementing a Robust Metal Detector Utilizing the Colpitts Oscillator with Toroidal Coil
}

\author{
${ }^{1}$ A.M.O. Obiazi, ${ }^{1}$ F.I. Anyasi, ${ }^{1}$ O. Jacdonmi, ${ }^{1}$ P.A. Otubu and ${ }^{2}$ I. Abhulimen \\ ${ }^{1}$ Department of Electrical and Eletronics Engineering, Ambrose Alli University, \\ P.M.B. 14, Ekpoma, Edo State, Nigeria \\ ${ }^{2}$ Department of Materials and Production, Ambrose Alli University, \\ P.M.B. 14, Ekpoma, Edo State, Nigeria
}

\begin{abstract}
Metal detectors are effective and useful security tools employed in strategic places such as airports, banks, stadiums, government houses and major hotels to detect the presence of ferro, para and dis-magnetic metals on persons, luggages and consignments. The study presents a metal detector comprising an RF oscillator, a detector/smoothing unit, comparator and a switching/signaling unit. A transistor colpitt oscillator is used with its inductor being a toroidal coil, thus acting as a transducer converting magnetic variations to voltage level changes through direct feedback mechanism. The tank circuit is set such that the feedback voltage is just sufficient to maintain oscillation. Magnetic variations caused by materials distort the initial set position, automatically cutting off oscillation and hence the transistor due to the biasing techniques employed. The comparator is set to switch to a negative voltage whenever the potential at its positive impact falls below $0.5 \mathrm{~V}$ and vice-versa. The performance of the detector was satisfactory, particularly for short-range applications. It detected both ferrous and non-ferrous metals like steel and aluminum at a range determined by the type of material and its relative size.
\end{abstract}

Key words: Colpitts oscillator, torus, magnetic distortion, metal detector, resonant frequency, ferromagnetic materials

\section{INTRODUCTION}

With heightened criminal activities crosses the world, it has become vitally necessary to prevent gunmen, knife men, kidnappers and suicide bombers from gaining access into sensitive and highly populated public places such as hotels, banks, airports, stadium, theaters, government and business headquarters. Since many of the deadly weapons used by these societal miscreants are made from combinations/synthesis of metallic materials, one effective way to stop these hardened and determined criminals in their track is the installation and use of metal detectors in these strategic public places.

These detectors help to identify and confirm the presence of metallic objects on persons, luggages and consignments, thus assisting security operatives to sort these individuals and luggages and determine if the metallic objects on them are for safe or harmful use. This has helped to arrest and stop potential killers, terrorists and similar criminals.

Scientists and engineers have been researching on and developing different techniques for effective metal detection. For example, Chekcheyev (2009), Kruger and Ewald (2008), Misakian et al. (2002) and Yamazaki et al. (2002) have developed analysis and on-line visualization for both hand-held and walk-through metal detectors (Chekcheyev, 2009; Kruger and Ewald, 2008; Misakian et al., 2002; Sharawi and Sharawi, 2007; Yamazaki et al., 2002). Sylvester and Omeragic $(1995,1996)$ and Chang-Hwan and Hyun-Kyo (2005) derived sensitivity maps for metal detector design and a numerical emulator for detectors.

In their research, the researchers carried out safety evaluation and effects of soil electromagnetic properties on metal detectors, their electromagnetic compatibility and their use for land mine detection (Brown et al., 2002; Wu et al., 2005; Das, 2006; Rennie et al., 1998; Witters et al., 2005). Brightom and English (1993), Joynt (1998), Kruger et al. (2006), Sato and Takahashi (2008) and Trevelyan (1998) developed methods for target depth estimation, reduction of false alarm rate and evaluation test procedures. Sensitivity test and the use of metal detectors for tracing submarine telecommunication cables were carried out by investigators (Asakawa et al., 1983;

Corresponding Author: A.M.O. Obiazi, Department of Electrical and Eletronics Engineering, Ambrose Alli University, P.M.B. 14, Ekpoma. Edo State, Nigeria 
Czipolt and Podney, 1989; Dhagat et al., 2008; Schulze and van Rieneu, 2007). In this research, combining the superior advantages of the toroidal coil and colpitts oscillator with a specific biasing technique and feed back mechanism produces a robust and low-cost metal detector for short-range applications.

\section{MATERIALS AND METHODS}

The metal detector: Figure 1 is a block diagram of the metal detector. The power supply unit could be a battery source or an a.c. source incorporating a rectifier and fitter.

Oscillators are essentially signal generators whose configurations are either Resistor-Capacitor (RC) type or Inductor-Capacitor (LC) type. Electrical oscillation is due to the interchange of electric and magnetic energy stored in the electric field of the capacitor and magnetic field of the inductor due to the $180^{\circ}$ phase shift in their operation. A specific type of LC oscillator, the colpitt oscillator was used in this design. Figure $2 \mathrm{a}, \mathrm{b}$ are examples of the colpitt oscillator, the simple common-base and common-collector variants. Key features of the colpitts oscillator are its simplicity (needs only a single inductor) and robustness. The feedback needed for oscillation is taken from a voltage divider made by the two capacitors.

Figure 3 and 4, respectively shows a practical colpitts oscillator and an ideal model of the oscillator.

In the ideal model of the colpitts oscillator (Fig. 4) parasitic elements and device non-linearities will be ignored. Acceptable results would still be realized. Ideal frequency of oscillation is:

$$
\text { fo }=\frac{1}{2 \Pi \sqrt{L \cdot\left[\frac{C_{1} C_{2}}{C_{1}+C_{2}}\right]}}
$$

Ignoring the inductor, the input impedance can be written as:

$$
\mathrm{Z}_{\text {in }}=\frac{\mathrm{V}_{1}}{\mathrm{i}_{1}}
$$

$V_{1} i_{1}$ is the input voltage and current, respectively. The voltage $V_{2}$ is given by :

$$
\mathrm{V}_{2}=\mathrm{i}_{2} \mathrm{Z}_{2}
$$

$Z_{2}$ is the impedance of $C_{2}$. The current flowing into $C_{2}$ is $i_{2}$ which is the sum of two currents:

$$
\mathrm{i}_{2}=\mathrm{i}_{1}+\mathrm{i}_{8}
$$

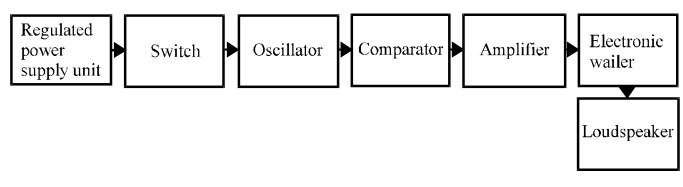

Fig. 1: Block diagram of the metal detector

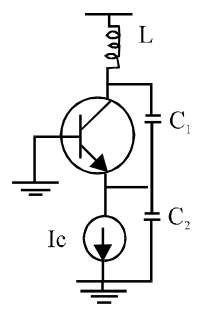

(a)

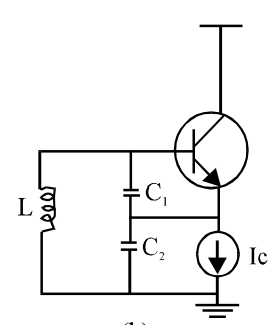

(b)
Fig. 2: Simplified colpitts oscillators; a) simple common-base; b) simple common-collector
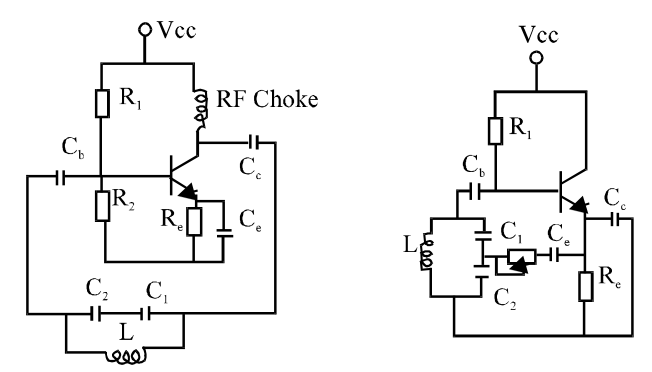

Fig. 3: Practical colpitts oscillators

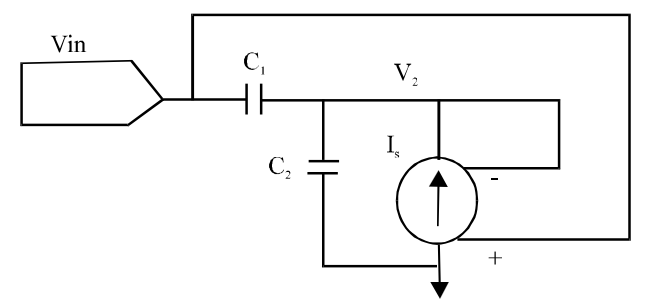

Fig. 4: Colpitts oscillator model

Where $i_{s}$ is the current supplied by the transistor; $i_{s}$ is a dependent current source shown by:

$$
\mathrm{i}_{\mathrm{s}}=\mathrm{g}_{\mathrm{m}}\left(\mathrm{V}_{1}-\mathrm{V}_{2}\right)
$$

$g_{m}$ is the transconductance of the transistor. The input current is written as:

$$
\mathrm{i}_{1}=\left(\mathrm{V}_{1}-\mathrm{V}_{2}\right) / \mathrm{Z}_{1(}
$$

Where $Z_{1}$ is the impedance of $C_{1}$. Solving for $V_{2}$ and substituting above yields: 


$$
Z_{\text {in }}=Z_{1}+Z_{2}+g_{m} Z_{1} Z_{2}
$$

The input impedance appears as the two capacitors in series with an interesting term, $R_{\text {in }}$ which is proportional to the product of the two impedances $\mathrm{R}_{\mathrm{in}}=\mathrm{g}_{\mathrm{m}} Z_{1}$. $Z_{2}$. If $Z_{1}$ and $Z_{2}$ are complex and of the same sign, $R_{\text {in }}$ will be a negative resistance which is a necessary condition for oscillation. If the impedances for $Z_{1}$ and $Z_{2}$ are substituted, $\mathrm{R}_{\mathrm{in}}$ becomes:

$$
\mathrm{R}_{\mathrm{in}}=\frac{-\mathrm{g}_{\mathrm{m}}}{\mathrm{w}_{2} \mathrm{C}_{1} \mathrm{C}_{2}}
$$

If an inductor is connected to the input, the circuit will oscillate if the magnitude of the negative resistance is greater than the resistance of the inductor. The frequency of oscillation is as shown in Eq. 1.

The toroidal coil: This is an inductive coil wound on a torus which is a surface of revolution generated by revolving a circle in 3 dimensional space about an axis coplanar with and not touching the circle (Fig 5).

To gain insight into the superior advantages of the toroidal coil, a matheatical examination of the geometry of the torus will be helpful. A torus can be defined parametrically by:

$$
\begin{aligned}
& x(u, v)=(R+r \cos v) \cos u \\
& y(u, v)=(R+r \cos v) \sin u \\
& z(u, v)=r \sin v
\end{aligned}
$$

Where:

$$
\begin{aligned}
\mathrm{u}, \mathrm{v}= & \text { In the interval }(0,2 \text { II) } \\
\mathrm{R}= & \text { The distance from the center of the tube to the } \\
& \text { center of the torus } \\
\mathrm{r}= & \text { The radius of the tube }
\end{aligned}
$$

An implicit equation in Cartesian coordinates for a torus radially symmetric about the z-axis is:

$$
\left(\mathrm{R}-\sqrt{\mathrm{x}^{2}+\mathrm{y}^{2}}\right)^{2}+\mathrm{z}^{2}=\mathrm{r}^{2}
$$

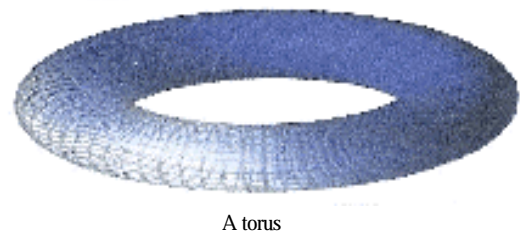

Fig. 5: A torus
And explicitly:

$$
f(x, y, z)=\left(R-\sqrt{x^{2}+y^{2}}\right)^{2}+z^{2}=r^{2}
$$

Clearing the square root and rotating $2 \Pi$ (equivalent to replacing $\mathrm{x}^{2}$ by;

$$
(r / 2 R)^{2}-y^{2} \rightarrow r=2 R \sqrt{x^{2}+y^{2}}
$$

produces a quadratic:

$$
\left(x^{2}+y^{2}+z^{2}+R^{2}-r^{2}\right)^{2}=4 R^{2}\left(x^{2}+y^{2}\right)
$$

The surface area and interior volume of this torus are shown by:

$$
\begin{gathered}
A=4 \pi^{2} \operatorname{Rr}(2 \pi r)(2 \pi R) \\
V=2 \pi^{2} R r^{2}=\left(\pi r^{2}\right)(2 \pi R)
\end{gathered}
$$

These equations are the same as for a cylinder of length $2 \Pi R$ and radius $r$ created by cutting the tube and unrolling it by straightening out the line running around the center of the tube. The losses in surface area and volume on the inner side of the tube happen to exactly cancel out the gains on the outer side. Thus, coils wound on toroids have the following advantages:

- High inductance for the physical space occupied

- No coupling or interaction with adjacent components

- Exceptional Q values when wound correctly

- Low cost, simple to mount and secure mechanically

Toroids are particularly useful as inductors in electronic circuits, especially at low frequencies. The formula for calculating the inductance of torod is:

$$
\mathrm{L}(\mathrm{nH})=\mathrm{N}^{2} \cdot \mathrm{A}_{1}
$$

$\mathrm{L}=$ Inductance in nanohenryns

$\mathrm{N}=$ Number of turns

$\mathrm{A}_{\mathrm{L}}=$ Inductance factor

It is known that when the entire space occupied by a field is occupied with a homogeneous magnetic material, the flux density $\mathrm{B}$ increases $\mathrm{N}$ times:

$$
\begin{gathered}
\mathrm{B}=\mathrm{B}_{0}+\mathrm{B}^{1}=\mu \mathrm{H}=\mu_{0}(\mathrm{H}+\mathrm{M}) \\
\mathrm{Hl}=\mathrm{NI}
\end{gathered}
$$

$\mathrm{M}$ is the intensity of magnetization. Considering a point $\mathrm{p}$, of distance $\mathrm{x}$ away from center of the field but contained in the filed: 


$$
\begin{gathered}
\mathrm{B}_{\mathrm{p}}=\mu_{0}\left(\mathrm{H}_{\mathrm{p}}+\mathrm{M}\right) \\
\mu \mathrm{H}_{\mathrm{p}}=\mu_{0}\left(\mathrm{H}_{\mathrm{p}}+\mathrm{M}\right) \\
\frac{\mu}{\mu_{0}}=1+\frac{\mathrm{M}}{\mathrm{H}_{\mathrm{p}}}=1+\mathrm{z} \\
\mu_{\mathrm{r}}-1=\frac{\mathrm{M}}{\mathrm{H}_{\mathrm{p}}}=\mathrm{z}=\text { susceptibility } \\
\mathrm{M}=\mathrm{H}_{\mathrm{p}}\left(\mu_{\mathrm{r}}-1\right)=\mathrm{H}_{\mathrm{p}} \mathrm{z}
\end{gathered}
$$

This affects the flux density at a shown coil position. The resulting filed becomes:

$$
\begin{aligned}
& \mathrm{B}=\mu_{0}(\mathrm{H}+\mathrm{M}) \\
& =\mu_{0} \mathrm{H}+\mu_{0} \mathrm{M} \\
& =\mu_{0} \mathrm{H}+\mu_{0}\left(\mu_{\mathrm{r}}-1\right) \mathrm{H}_{\mathrm{p}} \\
& =\mu_{0} \mathrm{H}+\mu_{0} \mathrm{zH}_{\mathrm{p}}
\end{aligned}
$$

The relative permeability $\mu_{\mathrm{r}}$ is a direct function of the type of metal in the presence or vicinity of the coil. Recall that inductance:

$$
\mathrm{L}=\frac{\mathrm{N} \phi}{\mathrm{I}}=\frac{\mathrm{NBA}}{\mathrm{I}}
$$

Substituting for B from Eq. 21, we have:

$$
\mathrm{L}=\frac{\mathrm{NA}}{\mathrm{I}} \mu_{0}[\mathrm{H}+\mathrm{HpZ}]
$$

But from Eq. 18, $\mathrm{H}=\mathrm{NI} / 1$ substituting in Eq. 22, we have the following Eq. 23 and $\mathrm{N}^{2} \mathrm{~A}_{\mathrm{L}}$ as shown in Eq. 16:

$$
\begin{aligned}
& \mathrm{L}=\frac{\mathrm{NA}}{\mathrm{I}} \mu_{0}\left(\frac{\mathrm{NI}}{2 \mathrm{r}}+\frac{\mathrm{NIr}^{2}}{2\left(\mathrm{x}^{2}+\mathrm{r}^{2}\right)}\right) \frac{3}{2} \times \mathrm{Z} \\
& =\mathrm{N}^{2} \mathrm{~A} \mu_{0}\left(\frac{1}{2 \mathrm{r}}+\frac{\mathrm{r}^{2}}{2\left(\mathrm{x}^{2}+\mathrm{r}^{2}\right)}\right) \frac{3}{2} \times \mathrm{Z}
\end{aligned}
$$

\section{RESULTS AND DISCUSSION}

Design specifications: Metals detectable-ferromagnetic materials having sufficiently high permeability such as cobalt, nickel, steel and iron.

Also included are paramagnetic materials of appreciable size, e.g., aluminum palladium, silver, platinum and rhodium. With sufficiently large size of diamagnetic material such as copper, lead and gold.

\section{Output signal indictor-LED and audible alarm}

Range of detection: Depends on material type and with respect to coil dimension. For large ferromagnetic materials with dimension equivalent to the coil dimension, range of $6 \mathrm{~cm}$ to be realized.

Oscillator design: The transistor configuration was used because of its satisfactory performance in the radio frequency range. The $\mathrm{RF}$ transistor $2 \mathrm{SC1} 674$ was chosen with the following characteristics as shown in Table 1.

The principle behind the operation of the metal detector is based on voltage comparison and switching. Thus, the oscillator must be biased in such a way to achieve this switching. One obvious way is to connect the transistor such that at one stage oscillation occurs and at another oscillation ceases. The change in voltage passes to a comparator which has a preset voltage level determined by the circuit's parameters. A colipitts oscillator with direct feedback from a resonant load to the input (Fig. 3b) was used.

The parallel LC circuit will have optimum impedance at resonant frequency. The resonant circuit was connected between the base and emitter since outputs was taken from the emitter. The fraction of voltage fed back to the emitter was $180^{\circ}$ out of phase with the baseemitter voltage. This biasing technique makes the oscillator operate in the class $\mathrm{C}$ whereby base current flows only in pulses to give a larger output power and high efficiency:

$$
\begin{gathered}
\mathrm{V}_{\mathrm{CC}}=\mathrm{V}_{\mathrm{CE}}+\mathrm{I}_{\mathrm{E}} \mathrm{R}_{\mathrm{E}} \\
\mathrm{V}_{\mathrm{CC}}-\mathrm{V}_{\mathrm{CE}}=\mathrm{I}_{\mathrm{E}} \mathrm{R}_{\mathrm{E}}
\end{gathered}
$$

Taking:

$$
\begin{aligned}
& I_{E} \approx I_{C} \\
& V_{C C}-V_{C E}=I_{C} R_{E}
\end{aligned}
$$

Table 1: Electrical characteristics $\left(\mathrm{T}_{\mathrm{a}}=25^{\circ} \mathrm{C}\right)$

\begin{tabular}{llclll}
\hline Symbols & Characteristics & Min. & Typ & Max. & Unit \\
\hline $\mathrm{h}_{\mathrm{FE}}$ & DC current gain & 40 & 90 & 180 & - \\
$\mathrm{C}_{\mathrm{ob}}$ & Output capacitance & - & 1.0 & 1.3 & $\mathrm{pF}$ \\
$\mathrm{NF}$ & Noise Figure & - & 3.0 & 5.0 & $\mathrm{~dB}$ \\
$\mathrm{f}_{\mathrm{T}}$ & Gain Bandwidth product & 400 & 600 & - & $\mathrm{MHz}$ \\
$\mathrm{Gpe}$ & Power gain & 18 & 22 & - & $\mathrm{dB}$ \\
$\mathrm{I}_{\mathrm{CBO}}$ & Collector cutoff current & - & - & 100 & $\mathrm{nA}$ \\
$\mathrm{I}_{\mathrm{EBO}}$ & Emitter citoff current & - & - & 100 & $\mathrm{nA}$ \\
$\mathrm{V}_{\mathrm{BE}}$ & Base to emitter voltage & - & 0.72 & - & $\mathrm{V}$ \\
$\mathrm{V}_{\mathrm{CE}(\text { sat) }}$ & Collector saturation voltage & - & 0.1 & 0.3 & $\mathrm{~V}$ \\
\hline
\end{tabular}


From specification, $I_{C}=1 \mathrm{~mA}$. For this class of operation:

$$
\begin{aligned}
& \mathrm{V}_{\mathrm{CE}}=\frac{1}{3} \mathrm{~V}_{\mathrm{CC}}=\frac{1}{3} \times 9=3 \mathrm{~V} \\
& \mathrm{~V}_{\mathrm{E}}=\mathrm{V}_{\mathrm{E}} \mathrm{R}_{\mathrm{E}} \approx \mathrm{I}_{\mathrm{C}} \mathrm{R}_{\mathrm{E}}=\mathrm{V}_{\mathrm{CC}}-\mathrm{V}_{\mathrm{CE}}=9-3=6 \mathrm{~V} \\
& \mathrm{R}_{\mathrm{E}}=\frac{\mathrm{V}_{\mathrm{E}}}{\mathrm{I}_{\mathrm{C}}}=\frac{6 \mathrm{volt}}{1 \mathrm{~mA}}=6 \mathrm{k} \Omega
\end{aligned}
$$

A standard value of $4.7 \mathrm{k}$ was used. Minimum voltage thus required at the base to effect transistor operation is:

$$
\begin{gathered}
\mathrm{I}_{\mathrm{E}} \mathrm{R}_{\mathrm{E}}+\mathrm{V}_{\mathrm{BE}}=1 \times 10^{-3} \times 4.7 \times 10^{-3}+0.7=5.4 \mathrm{~V} \\
\mathrm{~V}_{\mathrm{CC}}-\mathrm{I}_{\mathrm{B}} \mathrm{R}_{\mathrm{B}}=5.4 \\
\mathrm{I}_{\mathrm{B}} \mathrm{R}_{\mathrm{B}}=\mathrm{V}_{\mathrm{CC}}-5.4=3.6 \mathrm{~V}
\end{gathered}
$$

$R_{B}$ is the resistance needed to effect transistor operation but $\mathrm{I}_{\mathrm{C}} / \mathrm{I}_{\mathrm{B}}=\mathrm{h}_{\mathrm{FE}}=90$ (from transistor data):

Thus:

$$
\mathrm{I}_{\mathrm{B}}=\mathrm{I}_{\mathrm{C}} / \mathrm{I}_{\mathrm{B}}=\mathrm{h}_{\mathrm{FE}}=1 / 90 \mathrm{~mA}=11 \times 10^{-6}=11 \mu \mathrm{A}
$$

$$
\mathrm{R}_{\mathrm{B}}=\frac{3.6}{11 \times 10^{-6}}=0.33 \mathrm{~m} \Omega
$$

To enable the circuit operate in cut off, it requires a larger resistance such that voltage available at the base becomes in sufficient to put on the system. Choosing a value of $1 \mathrm{~m} \Omega$ results in a voltage shown by:

$$
9-\left(11 \times 10^{-6} \times 10^{+6}\right)=-2 \mathrm{~V} 9-\left(11 \times 10^{-6} \times 1^{+6}\right)=-2 \mathrm{~V}
$$

A voltage of $-2 \mathrm{~V}$ shows that the transistor is cut-off and no current flows.

Tank circuit design: From Eq. 1, the resonant frequency of a tuned circuit is:

$$
\mathrm{f}_{0}=\frac{1}{2 \Pi \sqrt{\mathrm{LC}}}
$$

where, in this case,

$$
\mathrm{C}=\frac{\mathrm{C}_{1} \mathrm{C}_{2}}{\mathrm{C}_{1}+\mathrm{C}_{2}}
$$

Oscillation is generated in the tank circuit from initial switching surge and it is sustained if the feedback voltage is of appropriate proportion. The parallel LC circuit will have optimum impedance at the resonant frequency. Since this impedance is resistive, the gain of the amplifier will be maximum. This parallel connection implies an ac voltage of $9 \mathrm{~V}$ peak to peak present at the base input. This voltage being $>5.4 \mathrm{~V}$ sets the transistor on anytime its value exceeds $5.4 \mathrm{~V}$ to achieve class $\mathrm{C}$ operation.

However, the choice of values of $\mathrm{L}$ and $\mathrm{C}$ is dependant upon choice of frequency, strength of magnetic field and base current required. The orientation of the coil is dependant on the required direction the magnetic field and for a circular coil, it is concentrated at the centre.

\section{The dimension of the coil:}

Former $=0.06 \mathrm{~m}$ (radius)

Cross section of coil, SWG 30-0.0031 m

Overall radius resulting from 110 turns $=0.065 \mathrm{~m}$

From Eq. 23, in the absence of any magnetic material:

$$
\begin{gathered}
\mathrm{L}=\mathrm{N}^{2} \mathrm{~A} \mu_{0} \times 1 / 2 \mathrm{r} \\
=110^{2} \times \pi \mathrm{r}^{2} \times 4 \pi \times 10^{-7} \times 1 / 2 \mathrm{r}=1.55 \mathrm{mH}
\end{gathered}
$$

Choosing a frequency of $57 \mathrm{kHz}$ in the radio frequency band:

$$
57 \times 10^{3}=\frac{1}{2 \pi \sqrt{1.55 \times 10^{-3} \cdot \sqrt{\mathrm{C}}}}
$$

This gives a capacity value of approximately $5 \mu \mathrm{F}$. Connecting two equal capacitor of $10 \mu \mathrm{F}$ in series to enable a tapping of voltage to the emitter will produce the required $5 \mu \mathrm{F}$. It is necessary that at some preset value of $\mathrm{C}_{1}$ or by including a resistor to limited voltage, the feedback voltage is insufficient to maintain oscillation. A $10 \mathrm{k} \Omega$ variable resistor was use for this purpose and through beat frequency interference response from a radio receiver, oscillating and non-oscillating conditions were determined. Measured value of variable resistor when oscillation just ceases was $3.5 \mathrm{k}$. An approximate voltage at the output of the oscillator during oscillation can thus be calculated. A peak voltage of 4.5 and $9 \mathrm{~V}$ peak is expected at the base. If $\mathrm{C}_{1}$ and $\mathrm{C}_{2}$ are of the same maguitude, a voltage of $4.5 / 2$, i.e., $2.25 \mathrm{~V}$ is expected across $\mathrm{C}_{2}$ :

$$
\mathrm{V}_{0}=\frac{4.7}{3.5+4.7} \times 2.25=1.28 \mathrm{~V}_{\text {Peak }}
$$

Thus, an approximate a.c. voltage having a peak value of $1.28 \mathrm{~V}$ is obtained from the emitter. Equation 23 enables to determine the range for a material which 
enclose the entire field of the coil knowing that frequency drift from setting due to the material will not exceed the audio frequency band. Since different materials with differing size are to be detected, the range will depend on the material and its size.

Comparator design: The design of the comparator simply involves setting resistor value such that at operation of the oscillator the voltage on the non-inverting input exceed that at the inverting input and vice-versa when the oscillator is cut off. When the oscillations go out, the transistor becomes automatically off because of the biasing technique used. Almost $0.5 \mathrm{~V}$ was chosen for the inverting input. Standard resistor values were used to achieve this, as shown in Fig. 6.

$$
\mathrm{V}_{2}=\frac{\mathrm{R}_{2}}{\mathrm{R}_{1}+\mathrm{R}_{2}} \times \mathrm{V}_{\mathrm{CC}}
$$

Choosing, $\mathrm{R}_{1}=68 \mathrm{k} \Omega$ and:

$$
\begin{gathered}
\mathrm{R}_{2}=4.7 \mathrm{k} \Omega \\
\mathrm{V}_{2}=4.7 \mathrm{k} / 72.7 \mathrm{k} \times 9 \mathrm{~V}=0.58 \mathrm{~V}
\end{gathered}
$$

The non-inverting input voltage is a measure of the emitter voltage. Calculated ac voltage on emitter $=1.28 \mathrm{~V}$ peak.

For effectiveness, a power amplifier was used in the switching stage. BD 235 with a current gain of $40-250$ is suitable. It is required that the oscillator be driven into saturation when an input base current is applied. Choosing a collector current of $2 \mathrm{~A}$ for saturation:

$$
\mathrm{I}_{\mathrm{B}}=\frac{2}{250}\left(=\mathrm{I}_{\mathrm{C}} / \mathrm{h}_{\mathrm{FE}}\right)=0.008 \mathrm{~A}
$$

The output voltage of the operational amplifier being approximately $8 \mathrm{~V}$, a base resistor and collector resistor values of 1 and $22 \mathrm{k} \Omega$ are appropriate.

Electronic wailer design: The general purpose power amplifies BD131 and 132 were used having a minimum gain $\left(\mathrm{h}_{\mathrm{FE}}\right)$ of 20 and collector current of $3 \mathrm{~A}$. The transistors were biased to operate at cut-off.

The electronic wailer produces an audible note that slowly rises in pitch until it get to a steady value. Resistor-capacitor combination determined the time rate of the charge and discharge of the capacitor. In Fig. 7, $C_{2}$

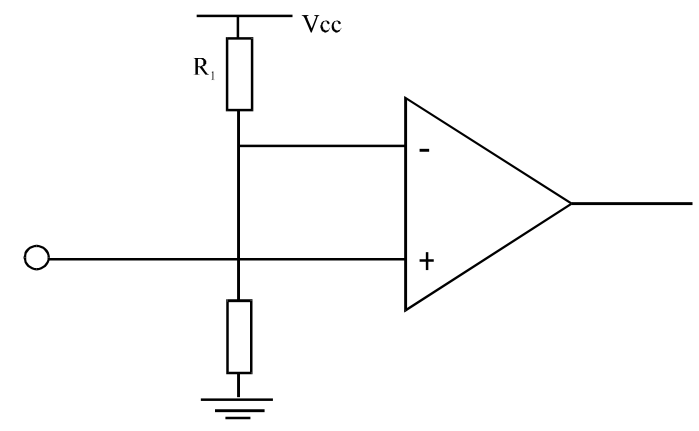

Fig. 6: The comperator circut

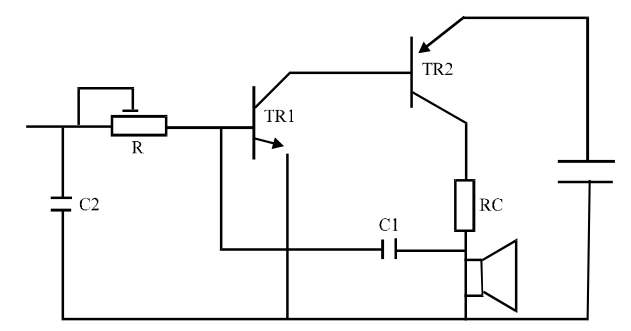

Fig. 7: Electronic wailer circuit

is responsible for producing the initial rising pitch of the note due to a rising voltage across it producing a rising current, hence a faster charge and discharge rate of $\mathrm{C}_{1}$ brought about by the rapid saturation and cut-off of both transistors $\mathrm{TR}_{1}$ and $\mathrm{TR}_{2} . \mathrm{TR}_{1}$ switches on when the voltage across $C_{1}$ reaches $0.65 \mathrm{~V}$. A rising current flows through it to $\mathrm{TR}_{2}$.

As the two transistors are biased to operate in saturation, the collector voltage of $\mathrm{TR}_{2}$ approaches $\mathrm{V}_{\mathrm{CC}}$ and is reflected back to the base of $\mathrm{TR}_{1}$ through $\mathrm{C}_{1}$. This effectively drives the transistor into saturation. With this, $\mathrm{C}_{1}$ becomes negatively charged and cuts off $\mathrm{TR}_{1}$ and subsequently $\mathrm{TR}_{2}$ until $\mathrm{TR} \mathrm{i}_{1} \mathrm{~s}$ voltage again reaches $0.65 \mathrm{~V}$. With proper selection of $\mathrm{C}_{1}$, speaker resistance and $\mathrm{R}$, a quick charge and discharge rate is obtained to produce a continuous sound as heard by the ear from the speaker. Choosing Ic of $\mathrm{TR}_{2}$ to be $4 \mathrm{~A}$ to effect its saturation, its base current becomes:

$$
\mathrm{I}_{\mathrm{B} 2}=\frac{4}{20}=0.2 \mathrm{~A}
$$

This is expected at the collector of $\mathrm{TR}_{1}$. The input current to $\mathrm{TR}_{1}$ is thus:

$$
\mathrm{I}_{\mathrm{B} 1}=\frac{0.2}{20}=0.01 \mathrm{~A}=10 \mathrm{~mA}
$$

The complete circuit of metal detector is shown in Fig. 8. 


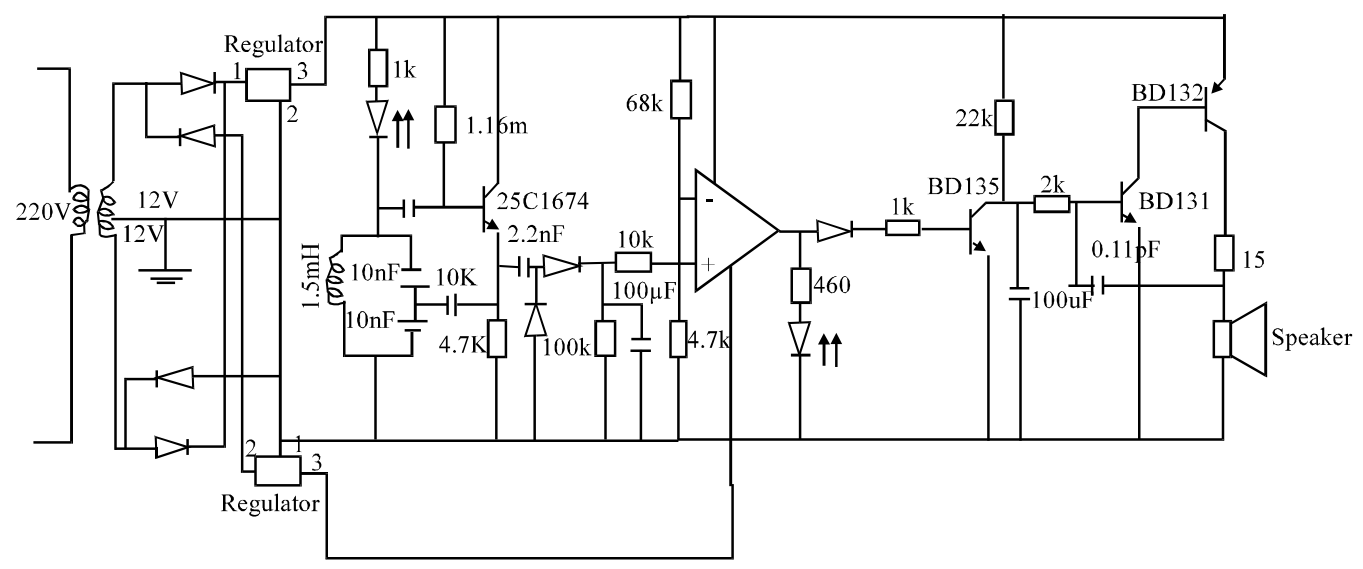

Fig. 8: The complete circuit of the metal detector

Performance of the metal detector: The performance of the metal detector was satisfactory. It is particularly suited for short range detection. Ferromagnetic, paramagnetic and diamagnetic materials were detected.

Detection was more effective with ferromagnetic materials as expected. For each class of material; the effectiveness of detection was proportional to the thickness of the material.

\section{CONCLUSION}

A metal detector of satisfactory performance designed with cheap but effective components has been described.

The design procedure for the various segments of the detector was shown. Practicing engineers working in airports, hotels, banks, security organization and large public places can easily replicate this robust, effective and low-cost metal detector.

\section{REFERENCES}

Asakawa, K., Y. Shirasaki and Y. Iwamoto, 1983. Metal detector for tracing submarine telecommunication cables. IEEE Tran. Instrumentation Measur., 32: 477-483.

Brightom, M. and M.J. English, 1993. Calculation of optimum spacing for a three coil axially symmetric metal detector. Elect. Lett., 29: 838-839.

Brown, C.L., A.M. Zoubir, I.J. Chant and C. Beynayake, 2002. Landmine detection using single sensor metal detectors. Proceedings of the IEEE International Conference on Acoustics, Speech and Signal Processing, May 13-17, IEEE Xplore, London, pp: IV-3948-IV-3951.
Chang-Hwan, I. and J. Hyun-Kyo, 2005. Numerical emulator for walk-through metal detectors using 3-D indirect boundary integral equation method. IEEE Trans. Instrumentation Measur., 54: 1166-1170.

Chekcheyev, S., 2009. A temperature-stable metal detector. IEEE Trans. Instrumentation Measur., 58: 1907-1910.

Czipolt, P.V. and W.N. Podney, 1989. Use of a superconductive gradiometer in an ultrasensitive electromagnetic metal detector. IEEE Trans. Magnet., 25: 1204-1207.

Das, Y., 2006. Effects of soil electromagnetic properties on metal detectors. IEEE Trans. Geosci. Remote Sens., 44: 1444-1453.

Dhagat, P., A. Jander and D. Luo, 2008. Metal detector coil arrangement for uniform internal and zero external sensitivity. J. Applied Phys., 103: 070E919-07E919-3.

Joynt, V.P., 1998. Mobile metal detection: A filed perspective. Proceedings of the 2nd International Conference on the Detection of Abandoned Land Mines, Oct. 12-14, Edinburgh, UK., pp: 14-18.

Kruger, H. and H. Ewald, 2008. Handheld metal detector with online and classification for the humanitarian mine clearance. Proceedings of the IEEE International Conference on Sensors, Oct. 26-29, Lecce, pp: 415-418.

Kruger, H., H. Ewald, T. Fechner and S. Bergeler, 2006. Advanced signal processing for reduction of false alarm rate of metal detectors for humanization mine clear. Proceedings of the IEEE Instrumentation and Measurement Technology Conference, April 24-27, Sorrento, Italy, pp: 1452-1456.

Misakian, M., J.P. Casamento and B. Laug, 2002. Development of emulator for walk-through metal detectors. IEEE Trans. Elect. Comp., 44: 486-489. 
Rennie, C., B. Arendse, M.R. Inggs and A. Longman, 1998. Practical measurements of landmine simulates using a SFCW radear, a pulse induction metal detector and an infrared camera. Proceedings of the 2nd International Conference on the Detection of Abandoned Land Mines, Oct. 12-14, Edinburgh, UK., pp: 182-186.

Sato, M. and K. Takahashi, 2008. Alis development for humanitarian demining and its evaluation test. Proceedings of the IEEE European Rader Conference, Oct. 30-31, Amsterdam, Netherlands, pp: 284-287.

Schulze, S. and U. van Rieneu, 2007. Computation of land mine signatures using domin decomposition with lagrange multipliers. IEEE Trans. Magnet., 34: 1189-1192.

Sharawi, M.S. and M.I. Sharawi, 2007. Design and implementation of a low-cost VLF metal detector with metal-type discrimination capabilities. Proceedings of the IEEE International Conference on Signal Processing and Communications, Nov. 24-27, Dubai, pp: $480-483$.

Sylvester, P.P. and D. Omeragic, 1995. Sensitivity of metal detectors to spheroidal targets. IEEE Trans. Geosci. Remote Sens., 33: 1331-1335.
Sylvester, P.P. and D. Omeragic, 1996. Sensitivity maps for metal detector design. IEEE Trans. Geosci. Remote Sens., 34: 788-792.

Trevelyan, J., 1998. Target depth estimation for a metal detector in the frequency domain. Proceedings of the 2nd International Conference on or Detection of Abandoned Land Mines, Oct. 12-14, Edinburgh, UK., pp: 218-221.

Witters, D.M., V. Buzduga, S. Seidman, W. Kainz, J. Casamento and P. Ruggera, 2005. Hand-held metal detectors and medical devices measurements and testing for electromagnetic compatibility. Proceedings of the IEEE 39th Annual International Canadian Conference on Security Technology, Oct. 11-14, Las Palmas, pp: 312-314.

Wu, D., R. Qiang, J. Chen, W. Kainz and S. Seidman, 2005. Safety evaluation of walk-through metal detectors. Proceedings of the IEEE International Symposium on Electromagnetic Compatibility, Aug. 8-12, IEEE Xplore, London, pp: 796-800.

Yamazaki, S., H. Nakane and A. Tanaka, 2002. Basic analysis of a metal detector. IEEE Trans. Instrumentation Measur., 5: 810-814. 